\title{
PENSAR GLOBALMENTE? A IDEIA, A IDEOLOGIA E OS LIMITES DO COSMOPOLITISMO
}

\author{
Barbara Will \\ barbara.will@dartmouth.edu
}

Em um momento histórico marcado pelo que Julia Kristeva recentemente denominou "A Crise do Sujeito Europeu", é interessante notar o correspondente aumento em popularidade, entre os intelectuais, de um termo que já fora considerado sinônimo da tradição europeia em suas pretensões mais universalizantes: "cosmopolitismo". Na América do Norte, ao menos, é como se este termo estivesse subitamente em todo lugar. Um recente levantamento das dissertações americanas concluídas nos últimos cinco anos mostra que cerca de 200 teses foram publicadas a respeito do conceito ou do discurso do cosmopolitismo; durante o mesmo período, quase trezentos artigos acadêmicos foram publicados sobre o assunto. Isso se tomando apenas as Humanidades; nas Ciências Sociais, e particularmente nas áreas de sociologia e de ciência política, o "cosmopolitismo" adquiriu importância como termo-chave em debates a respeito de globalização, transnacionalismo e pós-nacionalismo; e nas Ciências Naturais, especificamente em ecologia e estudos ambientais, o termo "cosmopolitismo" costuma vir acompanhado de "verde" (como em cosmopolitismo verde ou eco-cosmopolitismo).

"Cosmopolitismo", em resumo, é um termo que catalisa algo do Zeitgeist contemporâneo. E não é difícil entender a razão, já que parece 
se tratar de um dos poucos termos que possuímos capazes de captar e abordar as características únicas de nosso momento histórico global: de um lado, a junção entre explosão demográfica e diminuição dos recursos naturais, e, de outro, mundos culturais cada vez mais móveis, interconectados, dispersos e competitivos entre si. Ao mesmo tempo, não há dúvida de que os melhores críticos do cosmopolitismo consideramno um termo incômodo e escorregadio, prejudicado por um legado de usos baseados em desigualdade e opressão. Resumidamente, para alguns o termo parece dar corpo a uma ideologia liberal e eurocêntrica já desacreditada em uma roupagem nova e recém-perigosa.

O empenho aqui é em examinar os sentidos contestados de um termo compartilhado por áreas díspares, com projetos e desafios distintos, bem como explorar a forma e a possibilidade, na literatura e no cinema contemporâneos, de uma "subjetividade cosmopolita". Entretanto, apesar de não me alongar no debate sobre os méritos de termos contemporâneos concorrentes (como "transnacionalismo" ou "pós-nacionalismo"), continua sendo importante questionar brevemente o que parece se produzir com o termo "cosmopolitismo" que fica excluído de outras concepções de conexão e cidadania globais. Para além das suas conotações corriqueiras de sofisticação urbana e apreço pela diferença cultural, o cosmopolitismo carrega em si um forte imperativo moral e ético: um comprometimento com o que Walter Mignolo, por exemplo, vem chamando de "sociabilidade planetária" (2000, p.721). Outros pensadores cosmopolitas definiram seus projetos nos termos de um "comprometimento com os interesses da humanidade", "uma compreensãoampladeoutrasculturasecostumes", "umpensaresentirpara além da nação” (CHEAH e ROBBINS, contracapa), ou, na feliz formulação de Amanda Anderson, "uma delicada competência intersubjetiva dentro de um horizonte culturalmente diversificado" (ANDERSON, 1997, p.267, 275). Contudo, estes críticos também compartilham de um desconforto com o termo, enfatizando que os imperativos éticos do cosmopolitismo não são em si historicamente neutros ou livres de política e poder. Com efeito, o cosmopolitismo permanece hoje um termo prejudicado por conotações elitistas e eurocêntricas, assim como pelo espectro do capital global que alguns têm encarado como pré-condição necessária para a emergência de uma sensibilidade cosmopolita. E são precisamente essas conotações que dificultam a distinção entre um cosmopolitismo que deixa intactos os privilégios da elite global e um cosmopolitismo que criticamente desconstrói esses privilégios em nome de um mundo mais justo e habitável para todos. Isso foi bem formulado pelo sociólogo alemão Ulrich Beck, em seu ensaio "O Manifesto Cosmopolita": "Vivendo 
numa era de efeitos colaterais, temos que perguntar bem cedo: quais as consequências não-vistas e não-desejadas da nova retórica da 'comunidade global'? Quais os riscos, se a missão cosmopolita tiver êxito?” (BECK, 1999, p.13). Deixemos que as palavras de Beck sirvam de epígrafe a este ensaio.

"Cosmopolitismo" é, de fato, um termo com um rico legado histórico que se estende por mais de dois milênios: tendo-se originado na Grécia, com os filósofos cínicos, o termo reúne a visão do "cosmos", ou mundo, com o de "polis", ou cidade-estado. Habitantes das cidades também habitam o mundo, como compreendeu o cínico grego Diógenes

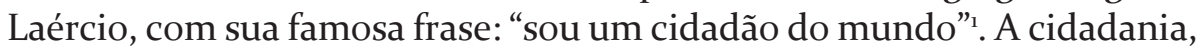
contudo, como bem sabemos, não é obviamente compatível com a pertença ao mundo; com efeito, ser cidadão em um lugar é precisamente não o ser em outro. A cidadania traz à frente todo tipo de deveres e exclusões, responsabilidades e proibições, vantagens e fronteiras. Podese argumentar que ser um cidadão é precisamente possuir deveres especiais, e, portanto, mais específicos do que genéricos, em relação às outras pessoas. Como então pensar a cidadania (necessariamente com suas delimitações) num horizonte de globalidade, pensar o paradoxo do "cidadão do mundo"? Este é um problema que assombra o termo cosmopolitismo desde o começo, questão que Zenão, o estoico grego, tentou resolver por meio de um apelo a um espírito universal: já que a razão divina constitui a lei do cosmos, todos os que vivem em conformidade com esta razão são passíveis de ser cidadãos do mundo. De maneira significativa, Zenão entendeu que o cosmopolitismo a) estava disponível, como sinal da "centelha divina", em todo ser humano e b) era inseparável da razão (como aquilo que iria guiar os povos para além de fidelidades instintivas, rumo à convivialidade universal). $\mathrm{Na}$ definição de Zenão, a ênfase recai sobre o mundano mais do que sobre o político, uma distinção que o termo "cosmopolitismo" ao mesmo tempo captura e busca transcender. Retornaremos a esta tensão entre o "mundano" e o "político" quando voltarmos nosso olhar ao modelo de eco-cosmopolitismo, ou cosmopolitismo ambiental.

Milhares de anos após os gregos antigos usarem o termo pela primeira vez, o cosmopolitismo tornou novamente ao palco central em

1. Para uma discussão ampliada do cosmopolitismo no mundo antigo, ver Fine \& Cohen (2008, p. 137-139). 
uma série de ensaios seminais escritos pelo filósofo Immanuel Kant em um período de 12 anos anterior e posterior à Revolução Francesa (FINE e COHEN, 2008, pp.139-145). Até então, como nos lembra Walter Mignolo, o cosmopolitismo havia sido tópico de discussão na "orbis universalis" do desígnio global dos cristãos medievais, assim como nos debates de Valladolid, durante o Quinhentos, sobre o questionável estatuto humano dos Ameríndios (MIGNOLO, 2000, pp.725-30). Foi Kant, contudo, quem primeiro estabeleceu os fundamentos para a discussão do cosmopolitismo que predominam hoje na filosofia política e em muito do pensamento social. Surgindo em um momento de levantes europeus - o fim da Guerra dos Trinta Anos; os primórdios da Revolução Francesa e Americana; o começo do sentimento nacionalista - os artigos de Kant sobre o cosmopolitismo reconheceram o quadro mais amplo ao qual tais movimentos políticos pareciam simultaneamente resistir e pressagiar. Para Kant, a questão era inerentemente moral. Para além de todas as reivindicações de estadismo absoluto ou proto-nacionalismo, havia padrões universais de direito baseados na "lei natural" - uma lei, em outras palavras, que é moralmente correta mais do que normativa, universal mais do que particular e contingente. Em "Ideia para uma História Universal de uma Perspectiva Cosmopolita”, Kant famosamente nos recorda de que a essência da natureza humana é a "sociabilidade insociável" - a tendência do ser humano em "estabelecer uma posição para si entre os seus pares, os quais ele não pode suportar e dos quais não pode prescindir". Dando ouvidos novamente ao estoico Zeno, Kant argumenta que é papel da Razão esclarecida impelir-nos, para além dessa dialética social essencial, rumo a uma "condição cosmopolita universal" na qual se pode realizar "a união civil perfeita das espécies humanas" (KANT, 2006, p.14).

O ideal kantiano e, de forma mais geral, a noção do Iluminismo ocidental de cosmopolitismo como o "plano e a derradeira intenção" progressiva do desenvolvimento humano sobre o tempo, subscreve o modelo predominante de cosmopolitismo em circulação entre os teóricos na ciência e filosofia políticas, bem como no pensamento social internacional. De Hanna Arendt a Martha Nussbaum a Seyla Benhabib a Jeremy Waldron, Kant é a pedra-de-toque para qualquer discussão de identidade pós-nacional em um mundo globalizado. Os artigos de Kant fornecem os termos e a visão para a ideia normativa ou prescritiva do cosmopolitismo, como um ideal rumo ao qual nos movemos de forma inevitável e voluntária; e a tradição kantiana permanece uma das formas mais ricas e importantes em que o termo tem sido atrelado a um ideal de possibilidade humana que transcenda particularidades individuais 
de localização, conjuntura e capacidade. As ideias de Kant, por sua vez, estão por trás do estabelecimento de instituições internacionais comprometidas com a manutenção daquele ideal, das Nações Unidas até, mais recentemente, os Tribunais Europeus dos Direitos Humanos. De fato, uma das mais férteis arenas para discussão na filosofia política contemporânea é o relacionamento entre cosmopolitismo e direitos humanos, já que o cosmopolitismo parece inscrever a única base real (ou ideal) sobre a qual os direitos humanos podem ser plenamente realizados, ao invés de serem mantidos reféns para sua execução e realização por estados-nação particulares. Conforme a ideia de "direitos humanos" cresceu de uma articulação de "crimes contra a humanidade" a "normas extensíveis ao refúgio, asilo e imigração", a obra de Kant tornou-se ainda mais relevante (BENHABIB, 2006). Certos cientistas políticos - por exemplo, Daniele Archibugi e David Held (2005), em seu livro Cosmopolitan Democracy: An Agenda for a New World Order - tem inclusive reimaginado a visão kantiana de uma "constituição cosmopolita" mundial para a era atual da globalização.

Contudo, é também este emparelhamento essencialmente gerencial de cosmopolitismo e globalização que mobilizou e estimulou o segundo maior modelo de cosmopolitismo, ao qual muitos se referem como "cosmopolitismo crítico" ou "o novo cosmopolitismo" (em oposição ao cosmopolitismo da filosofia ocidental, tido como antigo, comprometido e supostamente démodé). Este segundo modelo argumenta que não se pode separar o legado kantiano, incluindo a própria ideia de direitos humanos", de uma história opressiva de colonialismo ocidental e expansionismo econômico. Enquanto a tradição kantiana (e seus adeptos de hoje) largamente ignoram ou encobrem a ligação entre globalização e cosmopolitismo, o novo cosmopolitismo situa esta ligação em primeiro plano. Se, como diversos críticos tem notado, o conceito de cosmopolitismo emerge ao momento da expansão mercantil, então o conceito é, de alguma forma, inextricável da propagação do capitalismo imperial e de suas desigualdades econômicas estruturais. Nessa medida, o cosmopolitismo poderia ser visto como um eufemismo para um ferocíssimo expansionismo econômico do Ocidente: um termo que torna palatável um sistema ocidental abertamente opressivo e homogeneizador, e que permite aos que são contemplados pelos benefícios da globalização sentir-se confortáveis tanto por seus privilégios quanto por sua abertura de mente a respeito do mundo (encarnada nos "gostos" e "preferências" cosmopolitas), deixando enquanto isso sem exame as desigualdades estruturais que permitiram tais "contatos" internacionais. Não surpreende que esta segunda linhagem crítica de pensamento sobre o 
cosmopolitismo tenha emergido com a maior força dos domínios da teoria pós-colonial, que interroga as deficiências do cosmopolitismo filosófico liberal de veio kantiano, situando no espaço da "diferença colonial" o novo cosmopolitismo crítico ${ }^{2}$. Isso também gerou uma poderosa resposta da parte de Jacques Derrida, autor que examina o grande "espaço" aberto pelo pensamento de Kant, assim como seu potencialmente "piedoso e irresponsável desejo" (DERRIDA, 2007, p.23).

Muitos teóricos do cosmopolitismo crítico tiveram como foco a noção kantiana de "direitos universais do Homem" - o que Hannah Arendt, por exemplo, designa como o legado mais duradouro da filosofia de Kant. Como escreve Kant em Rumo à Paz Perpétua, uma das suas mais famosas conferências sobre o cosmopolitismo: "toda a política deve dobrar os joelhos diante do direito [humano], mas podendo esperar alcançar, ainda que de forma gradual, o ponto em que brilhará perpetuamente" (KANT, 2006, p.104). Para tais teóricos, entretanto, é precisamente a questão dos direitos humanos que "permanece [...] um entrave para os projetos cosmopolitas" (MIGNOLO, 2000, p.725). A própria noção de "humano" à qual se referem os "direitos humanos" é vista como um conceito menos filosófico ou racional do que histórico, emergindo historicamente "no horizonte colonial da modernidade" - no local de encontro com o Outro colonial não-humano. Nesse sentido, pode-se contrastar de forma proveitosa o discurso de Kant sobre os direitos com suas "conferências antropológicas”, onde ele busca uma classificação racial do planeta pela cor da pele, escrevendo que "o caráter inato de um povo é uma função de sua constituição racial; está 'no sangue”" (KANT, 2006, p.184)3. Em oposição ao - e, com efeito, no lugar de produção do - sujeito kantiano moral, livre, consciente de si e, sobretudo, dotado de razão, jaz este Outro colonial não-humano. Este é, portanto, o ponto cego no centro do cosmopolitismo kantiano, já que a noção de "humano" sobre a qual esta teoria se predica é aquilo que Hegel chamaria de um "falso universal" - o apelo a um princípio universal que se aplica unilateralmente ao originador do apelo.

Joseph Slaughter se encarrega dessa questão em seu recente livro Direitos Humanos Ltda., uma crítica pós-humanista da ideia dos direitos humanos que estabelece, de forma notável, seu vínculo com a emergência do Bildungsroman na Europa. O autor argumenta que o discurso dos direitos humanos começa "por imaginar o sujeito-cidadão normativo,

2. Como introdução à crítica pós-colonial do cosmopolitismo, ver toda a edição de Public Culture, ed. Carol Breckenridge, 12: 3 (Fall, 2000).

3. Ver também Zammito (2002). 
detentor de direitos, [como] uma personalidade humana 'universal' abstrata que 'pressupõe formas particulares de incorporação e exclui ou marginaliza outras' [...] A partir desta ficção permissiva, o excluído e o marginal emergem como criaturas que carecem [...] daquilo que o sujeito-cidadão incorporado desfruta". O apelo cosmopolita aos Direitos Humanos, Slaughter conclui, "frequentemente serve para recentralizar os sujeitos tradicionais da história, dessa vez como sujeitos da benevolência e da sentimentalidade intervencionista humanitária”. Por baixo desse impulso humanitário, entretanto, jaz o sujeito acrítico e autocentrado do privilégio, quem, ao contrário do beneficiário marginal do discurso dos direitos, celebra "uma carreira normativa de desenvolvimento livre e completo da personalidade humana” (SLAUGHTER, 2007, p.43, 324, 4).

Em seu recente ensaio, "As Intimidades de Quatro Continentes", Lisa Lowe oferece uma poderosa crítica de um humanismo europeu moderno

\begin{abstract}
que traduz o mundo por meio de uma economia de afirmação e esquecimento, em um regime de liberdade desejante. A afirmação do desejo de liberdade está tão habitada pelo esquecimento de suas condições de possibilidade que cada articulação narrativa de liberdade é assombrada por seu enterro, pela violência do esquecimento. Aquilo que conhecemos como "raça" ou "gênero" são os traços desse esquecimento humanista moderno. Eles residem na, e são constitutivos da, narrativa moderna da liberdade, mas nem estão plenamente determinados, nem exauridos por seus fins (LOWE, 2006, p.206-207).
\end{abstract}

Se vemos essa "narrativa moderna da liberdade" como contérmina com a noção humanista moderna de cosmopolitismo, então a questão da raça e do gênero - ou, ao meu ver, ainda mais poderosamente, a de classe social torna essa narrativa problemática por definição. Um esforço cosmopolita dominante para transcender as particularidades em nome da liberdade e da conexão global na esfera política oblitera a história da própria ideia de "liberdade", tomando-a como uma afirmação assentada na existência do não-livre e não-civilizado. Nesse sentido, o cosmopolitismo éinteiramente uma ideologia que favorece a elite. De forma crucial, entretanto, aqueles que habitam os espaços demarcados por "raça", "gênero", ou "classe" aqueles cuja diferença particular precisa ser renegada pelas pretensões universalizantes do cosmopolitismo - podem ter a capacidade especial de forjar conexões por meio de linhas de opressão e sobrevivência compartilhadas. É a estes “outros cosmopolitanos" que devemos retornar brevemente.

Uma das mais contundentes acusações literárias das pretensões universalizantes do cosmopolitismo ocidental pode ser encontrada no romance Cosmópolis, do americano Don DeLillo (2003). Aqui, a ideia 
de cosmopolitismo é despida até sua essência selvagem de expressão cultural do poder hegemônico ocidental e do capitalismo global predatório. Não mais espaço da "sentimentalidade humanitária", a cosmópolis pós-moderna é um lugar dividido nitidamente entre os que tem e os que não, entre os super-ricos e poderosos e os marginais, excluídos e violentos. Estória dos esforços de um homem para cruzar Nova Iorque numa limosine durante um único dia em 2000, o romance é também uma paródia amarga do Ulisses de Joyce e do seu estatuto representativo como ícone do modernismo literário ocidental. Ao contrário do Ulisses, Cosmópolis analisa as ruínas da modernidade e descobre, não uma rica veia de possibilidade subjetiva, mas somente o desenraizamento, o desabrigo transcendental, o vazio interior do indivíduo. São estas características que coletivamente definem o sujeito cosmopolita Eric Packer. Um "cidadão do mundo com um par de colhões modelo Nova Iorque", como ele se descreve; um bilionário capitalista das finanças encapsulado em sua limosine branca à prova de balas, adornada de múltiplos televisores, Packer relaciona-se com o mundo inteiramente com e pela lente da tecnologia (uma das muitas ironias do romance é que Packer despacha pelos fluxos de informação do ciberespaço enquanto sentado no congestionamento sem fim da Manhattan central). Sua existência hermética é ironicamente justaposta ao ambiente multicultural de Nova Iorque - com seus "restaurantes gregos e etíopes, taxistas sulasiáticos, garçons hispanofalantes, turistas suecos e bancos israelitas" (ESTEVE, 2008, p.255). A essa turba multicultural Eric Packer não dirige nem curiosidade nem empatia, apenas uma consciência amarga da impossibilidade de conexão humana num espaço mediado pelo cibercapitalismo. Nas mãos de DeLillo, o cosmopolitismo contemporâneo toma duas formas: a tecno-alienação compartilhada das elites brancas, marcada por aquilo que DeLillo chama "a puta [dead-ass] deriva da sua anomia urbana pessoal", e o desespero do marginal e excluído, que "não tem nada a perder" e faz uso da violência como meio de "contar pra alguma coisa" (DELILLO, 2003, pp.147, 194, 187).

Se o romance de DeLillo captura, com exatidão mordaz, a preocupação do cosmopolitista crítico de que o termo "cosmopolitismo" seja pouco mais do que uma fachada para o privilégio e poder primeiromundistas, a questão então permanece: qual é o valor de um termo como "cosmopolitismo"? Qual a utilidade da ideia de cosmopolitismo, de uma perspectiva crítica ou pós-colonial? Pode-se reabilitar o termo para as vítimas da globalização, ou será ele relevante apenas para os Eric Packers alienados deste mundo? É possível argumentar que o cosmopolitismo tem pouca relevância para aqueles a quem a visibilidade 
e o poder já foram negados e que, em última análise, ele trabalha contra as comunidades cuja localidade e enraizamento já estão sob o cerco do capital global. Contudo, este argumento corre ainda o risco de tornar sua postura crítica irrelevante para um mundo mais amplo no qual "pensar globalmente" transformou-se em imperativo ético. E é possível argumentar que a novidade do nosso mundo contemporâneo não são de fato as experiências mundo afora das elites viajeiras - cuja sensibilidade, afinal, recua em 150 anos para aquelas figuras de tipo flâneur das grandes metrópolis do Oitocentos ocidental. Ao invés disso, novos enquadramentos éticos são requisitados para colocar-se em acordo com o simples fato da intensificação do movimento global por parte de populações marginais - com o fato de que um crescente número de populações pobres, não-brancas foi desterritorializada e lançada à deriva pelo mundo graças a privações de guerras, fome, dificuldade econômica e falta de oportunidade. A questão se mantém: poderia um termo como "cosmopolitismo" ser refuncionalizado de forma a descrever as experiências daquele número crescente de pessoas deslocadas num mundo pós-moderno imensamente móvel?

Dadas essas questões, é interessante considerar um subgrupo de pensadores dentro do segundo modelo de cosmopolitismo - o modelo do dito "cosmopolitismo crítico" - que argumenta, aparentemente contra a maré, que, longe de estar no "horizonte" do discurso, o Outro nãoocidental na verdade é a epítome do sujeito cosmopolita contemporâneo. Por exemplo, na recente edição especial sobre "Cosmopolitismo" da revista Public Culture, da Duke University, os editores escrevem:

\footnotetext{
Os cosmopolitas de hoje são frequentemente as vítimas da modernidade, traídos pela ascendente mobilidade do capitalismo e despojados daqueles confortos e costumes da pertença nacional. Refugiados, povos da diáspora e migrantes e exilados representam o espírito da comunidade cosmopolítica. Com muita frequência, no Ocidente, tais povos são agrupados juntos no vocabulário da vitimização e chegam a ser reconhecidos como o "problema" do multiculturalismo para o qual o liberalismo tardio extende sua generosa promessa de existência plural [...] Tal benevolência é frequentemente bem intencionada, mas falha em reconhecer a crítica da modernidade que os cosmopolitas minoritários incorporam em seu testemunho histórico do século XX (POLLOCK, BHABHA, BRECKENRIDGE, 200o, p.582).
}

Levando-se isto em consideração, a globalização é mais do que um sistema econômico de desigualdade e desenvolvimento assimétrico; ela é também produtora de uma nova classe de sujeitos migrantes ou diaspóricos cuja emergência, ao mesmo tempo, "carrega o testemunho" das devastações da globalização que deram origem aos seus deslocamentos $e$ oferece 
a possibilidade de uma identidade nova e transnacional. Ao contrário da sua contraparte primeiro-mundista que viaja mundo afora (aquilo que podemos chamar "cosmopolitas majoritários"), os "cosmopolistas minoritários" são os trabalhadores e refugiados estrangeiros, os forasteiros ilegais e os exilados políticos, aqueles que coletivamente partilham a experiência do transplante forçado ou, de outra forma, da migração desesperada e que, então, problematizam a ideia do sujeito racional e auto-realizado do cosmopolitismo iluminista. Mais do que simplesmente um grupo de "vítimas" necessitando (através da legislação dos direitos humanos) ser envolvida no abraço tolerante do liberalismo ocidental, os cosmopolitas minoritários, por sua própria existência, põem em questão as pretensões universalizantes do pensamento liberal do Ocidente. Produzidos como um efeito de devastações da globalização, estes sujeitos "minoritários" então possuem uma perspectiva especial dos aspectos tanto positivos quanto negativos da experiência cosmopolita. Através do deslocamento, estes cosmopolitas minoritários se tornaram não "cidadãos do mundo", mas testemunhas do mundo, uma designação em si mesma híbrida, no entremeio, nas bordas da pertença nacional, sendo, portanto, crítica. De fato, podemos dizer que esses sujeitos passaram a viver a ideia do "cosmopolitismo crítico".

James Clifford, um dos primeiros e mais importantes teóricos do novo cosmopolitismo, tratou dos "cosmopolitas discrepantes" já em 1992, e suas palavras ainda ressoam neste contexto. Ele escreve:

Temos que lidar com o fato de que viajantes se deslocam sob fortes compulsões culturais, políticas e econômicas, e que certos viajantes são materialmente privilegiados, enquanto outros são oprimidos [...] [Na verdade,] culturas de deslocamento e transplante são inseparáveis das histórias específicas e frequentemente violentas de interações econômicas, políticas e culturais, histórias que geram aquilo que poderíamos chamar cosmopolitas discrepantes (CLIFFORD, 1992, p.108).

Afastando-se a ideia de cosmopolitismo de uma associação exclusivamente elitista com o sujeito-cidadão do Primeiro Mundo e usando-a para descrever, por exemplo, um refugiado sudanês no Cairo ou um trabalhador mexicano ilegal nos Estados Unidos, Clifford ao mesmo tempo desconstroi o termo "cosmopolita" e o realoca de sugestivas maneiras. Distanciando o termo de suas associações com cidadania (como na frase de Diógenes, "eu sou um cidadão do mundo"), Clifford permite que ele descreva tanto uma posição anti-nacional quanto uma transnacional (e, de fato, Clifford foi severamente criticado, por Timothy Brennan [1997] e outros, por fazer vista grossa a um "nacionalismo defensivo" dos 
"países emergentes terceiro-mundistas"). Contudo, pela recusa em deixar que o nacional ou local transforme-se no lugar da formação identitária cultural, e pelo reconhecimento de que uma perspectiva cosmopolita pode emergir da deportação ou do deslocamento forçado ou relutante, Clifford abre caminho para uma compreensão das conexões cosmopolitas muito mais ampla do que a de muitos críticos. Estas conexões podem surgir não exatamente das condições de boa vontade e privilégio, mas da dificuldade e da sobrevivência compartilhada, assim como do ato básico de carregar o testemunho dos efeitos desumanizadores da globalização. O cosmopolitismo, em outras palavras, pode descrever tanto uma crítica minoritária da globalização como seu abraço majoritário.

De muitas formas, a arte, a literatura e o cinema capturaram essa ideia de cosmopolitismo crítico ou minoritário com maior agudeza do que a análise política e cultural. Textos bem conhecidos como Os Versos Satânicos, de Salman Rushdie, Tempo de Migrar para o Norte, de Tayeb Salih, ou Omeros, de Derek Walcott, traçam as íntimas relações que literalmente atravessam os mundos Ocidental e não-Ocidental, descrevendo sujeitos marginais híbridos que, nas palavras de Rushdie, exemplificam a ideia do viajante cosmopolita. Outros textos menos conhecidos, como Pagoda, de Patricia Powell, que examina as relações entre imigrantes chineses, indianos e africanos no Caribe, representam um novo e instigante gênero literário. As raízes desta estética literária podem ser claramente traçadas até a obra dos escritores modernistas expatriados do começo do século XX - por exemplo, o escritor brasileiro Mário de Andrade, cuja novela Macunaíma gerou seu próprio subgênero de pirateações cosmopolitas. $\mathrm{O}$ cinema contemporâneo é também rico em exemplos de cosmopolitismo minoritário, como por exemplo o filme turco-alemão Do Outro Lado (The Edge of Heaven, 2007), o qual imagina as peregrinações de imigrantes turcos na Alemanha e as de imigrantes alemães na Turquia na medida em que estes dois grupos que se mesclam e se constituem um ao outro.

Um exemplo do cinema contemporâneo a se considerar é o filme de Stephen Frears Coisas Belas e Sujas (Dirty Pretty Things, 2002). Estória do mercado paralelo de órgãos humanos em Londres, o filme exibe um elenco internacional de personagens, incluindo um médico nigeriano que trabalha ilegalmente como taxista, uma empregada turca, também ilegal na Inglaterra, por quem ele se interessa, um gerente de hotel espanhol, que conduz o tráfico ilegal de órgãos, um agente funerário chinês, dono de um sweatshop indiano, e inúmeros outros (de fato, um dos mais notáveis aspectos do filme, como uma produção de grande orçamento, é não possuir nenhum papel principal representado por um personagem 
europeu branco). A estória mostra Juan, o traficante de órgãos, conduzindo um hábil negócio em seu hotel, retirando e vendendo rins de imigrantes ilegais em troca de passaportes falsificados. Tudo muda quando Okwe, o médico nigeriano, droga secretamente Juan, retira o rim dele e o vende para o contato desconhecido dele. Numa cena significativa, Okwe, a empregada turca Senay e a prostituta londrina Juliette - todos juntos no complô contra Juan - encontram o contato do Primeiro Mundo de Juan e explicam quem são: "Somos as pessoas que você não vê. Somos os que dirigem seus táxis. Limpamos seus quartos. Chupamos seus pintos" (FREARS, 2002). Conforme o contato dá de ombros e entrega o dinheiro pelos órgãos de Juan, não se ouve nada mais do que os subalternos da globalização contemporânea "retrucando" à fonte de sua exploração. Por fútil que seja a sua fala, por severa que seja a sua continuada exploração, a cena é ainda assim poderosa. São expostos os sentidos compartilhados de sobrevivência e testemunho, assim como o desenraizamento forçado experienciado por esses "cosmopolitas minoritários".

Pode-se dizer que o ponto de discórdia tanto para os cosmopolitas "majoritários" do Primeiro Mundo quanto para os cosmopolitas "minoritários" pós-coloniais é inevitavelmente aquilo que Carl Schmitt chama de "o conceito de político". Schmitt define o político como uma distinção entre amigo e inimigo que demarca as fronteiras entre os de dentro e os de fora, os cidadãos e os forasteiros, o Ocidente e o Resto. Para Schmitt, "O inimigo político não tem que ser moralmente mau ou esteticamente feio; ele não tem que surgir como competidor na economia; e pode inclusive ser vantajoso estabelecer negócios com ele. Mas ele é, de qualquer maneira, o outro, o estranho; e é suficiente para a sua natureza que ele seja, de maneira especialmente intensa, algo existencialmente distinto e alheio, de forma que, em caso extremo, conflitos com ele são possíveis" (SCHMITT, 2007, p.27). Para os dois modelos de cosmopolitismo que viemos analisando até agora, é esta arena intratável da política - da mentalidade do "nós contra eles" por parte dos estados-nação - que continuamente parece subverter, e de fato talvez tornar impossível, qualquer projeto cosmopolita.

Contudo, o terceiro modelo de cosmopolitismo em circulação hoje é um modelo que, consciente de si, reivindica transcender o político que, poderíamos dizer, coloca sua ênfase ética mais no lado "cósmico" do que no "político" do cosmopolitismo. É o movimento do "eco"cosmopolitismo ou cosmopolitismo verde - um movimento que focaliza menos a convivialidade planetária do que a sobrevivência planetária, e que vê nas depredações do industrialismo moderno ao redor do globo um terrível futuro para os seres vivos como um todo. É claro, a política 
entra em discussão quando nações debatem o gerenciamento dos riscos de mudança ambiental, e quando se torna claro que os pobres sofrem desproporcionalmente com as políticas do Primeiro Mundo em questões como o aquecimento global e a eliminação de lixo tóxico. De qualquer forma, o cosmopolitismo ambiental toma como ponto de partida o ponto de vista da "Ecologia Profunda" (Deep Ecology), segundo o qual somos todos parte de um ecossistema interrelacionado; segundo o qual mudanças no sistema terão efeitos bombásticos e imprevistos ao redor do globo; segundo o qual não há posição suficientemente privilegiada para escapar desses efeitos. Como escreveu Marshall McLuhan: "a ecologia transfere o 'Fardo do Homem Branco' para os ombros do 'ZéNinguém”" (citado por SPIVAK, 1998, p.341). O eco-cosmopolitismo, outrossim, transfere o fardo da responsabilidade ética para os ombros de cada homem e mulher vivos.

Ao contrário do modelo kantiano de cosmopolitismo, o ecocosmopolitismo não pode fundamentar sua ética na ideia de direitos, já que (como argumenta o próprio Kant) é o mundo natural que funciona como algo dado a partir do qual a noção de direitos emerge. Ecocosmopolitas podem falar sobre o direito dos animais e plantas, dos rios e florestas, mas este "discurso de direitos" parece aprisioná-los na armadilha do "especismo" antropocêntrico que é, na verdade, o ponto de partida de sua crítica. Apesar de tomar muitas formas, incluindo o movimento pró-capitalista do "desenvolvimento sustentável", a maioria dos ecocosmopolitas está mais próxima em espírito do novo cosmopolitismo crítico, que vê no capitalismo industrial moderno e no discurso dos "direitos" a fonte de um processo da marginalização do não-ocidental que, por definição, é exploradora. Contudo, é ainda importante enfatizar que o ponto de partida do eco-cosmopolitismo é menos a exploração em particular e a política em geral do que a questão maior da sobrevivência do planeta. Se pode ou como pode este modelo de cosmopolitismo ter algum duradouro impacto social ou ao menos teórico, entretanto, eis mais uma questão suscitada pelo termo "cosmopolitismo".

Alguns dos problemas que o eco-cosmopolitismo enfrenta são os mesmos que se referem a uma noção iluminista mais antiga de cosmopolitismo. Como observamos, um projeto universalizante que falha em reconhecer a diversidade cultural e a desigualdade de classe e econômica corre o risco de tornar-se um "falso universal". Considere-se apenas a recente "Carta da Terra" apresentada à Cúpula da Terra das Nações Unidas em 2002, um texto que se apresenta como "uma iniciativa cidadã global que apoia e promove uma visão ambiental cosmopolita" (MACGREGOR, 2004, p.87). Na verdade, como os críticos têm notado, 
esta "iniciativa cidadã global" parece estar grandemente orientada para o ocidente e para o desenvolvimento e no seu amplo escopo falha quase completamente em reconhecer as complexidades do uso ambiental e das comunidades locais. Outros problemas que se aderem a esta forma de "pensar globalmente" incluem o sentimentalismo New Age (o movimento "A Terra é nossa Mãe") e o chamado "globalismo banal" - baseado numa invocação e transcendência simultâneas da diferença cultural -, todos incorporados pela ilustração na capa da Carta da Terra, a qual mostra "rostos multiculturais sorridentes flutuando no espaço por cima de imagens de vida selvagem e quedas-d'água” (MACGREGOR, 2004, p.92).

Algumas das dificuldades - e possibilidades - desta forma de pensamento cosmopolita foram capturadas na obra do escritor alemão W. G. Sebald, um autor que vem sendo cada vez mais celebrado pelos críticos contemporâneos por sua exploração comovente e vívida dos temas da memória, perda e deslocamento, particularmente à luz do Holocausto e da Segunda Guerra Mundial. A meu ver, Sebald é também um dos mais finos intérpretes da crise ambiental global em curso ${ }^{4}$. Em sua representação do impacto humano no mundo natural, particularmente na era industrial moderna, Sebald produziu uma denúncia devastadora da vontade de conhecer como um ato de violência sublimada. Ao mesmo tempo, a escrita de Sebald enreda seu próprio texto e o leitor neste ato de violência, problematizando a ideia de que possa haver uma forma de lidar com a natureza que de algum modo escape a essa violência. Isso pode ser visto de forma especialmente poderosa numa longa passagem - longa demais para ser facilmente extraída - sobre o destino do humilde arenque (SEBALD, 1999, pp.54-59), de seu livro Os Aneis de Saturno, um relato das andanças de Sebald pela Ânglia Oriental na Inglaterra (modelado livremente em talvez um dos primeiros textos eco-cosmopolitas, o Walden de Henry David Thoreau).

O estilo de Sebald tem sido descrito como "vertiginoso" (e, de fato, Vertigem é o título de um dos seus livros), e essa palavra descreve à perfeição a sensação que se tem, quando se lê Sebald, de "cambalear" ao longo de sua prosa enquanto ela pula de ponto em ponto, detalhe em detalhe, memória em memória, com um inevitável ponto final que leva a um fim irônico não importa que tópico venhamos explorando. $\mathrm{O}$ poder dessa escrita reside em seu fluxo metonímico: uma ideia ocasiona a outra, um significante conduz a outro, sem a impressão clara de nenhuma

4. Enquanto Sebald foi discutido por Eric Santner em On Creaturely Life (2006) e outros em termos do seu interesse na fronteira animal-humano, pouco foi feito da sua perspectiva eco-cosmopolita mais ampla. 
lógica sobrejacente. Decerto não há um julgamento moral manifesto que percorra o relato da história do arenque, da pesca predatória no Mar do Norte aos edificantes filmes pedagógicos da Alemanha, passando pela vivissecção nas peixarias de Paris e pelo bizarro pós-vida da pele brilhante do arenque. E, contudo, nesta passagem sobre o arenque há uma lógica, sendo esta indiretamente de ordem moral, que passa por algo assim: exploramos o mundo natural por lucro e conhecimento, e fazemos isso em nome da "conquista implacável das trevas" (as irônicas palavras finais da passagem), e no processo destruímos todo mistério e beleza no mundo. Não surpreende que, a essa passagem do arenque, siga-se uma longa discussão sobre os campos de concentração nazistas em Bergen-Belsen. Qual é, Sebald parece indagar, a diferença entre o nosso mais perverso tratamento de outros seres humanos e o nosso tratamento do mundo natural? Estas são as questões que Carl Schmitt, o brilhante crítico e nazi-propagandista, julgaria irrelevantes para os domínios do político. Contudo, o que problematiza esta "moral" metapolítica é a nossa desconfortável sensação de que o próprio texto de Sebald está reproduzindo esta lógica: é o texto (e por implicação o leitor) que meticulosamente observa, mensura, representa visualmente e contempla o arenque, de uma maneira não distinta daquela do vivisseccionista francês "Noel de Marinière", que mutilava peixes vivos a fim de ver quanto tempo poderiam sobreviver em tais condições. Aqui, Sebald parece estar tanto comentando quanto exemplificando a lógica da famosa máxima de Wordsworth: "Nós matamos para dissecar". No fim, essa escrita não evita a violência da qual fala, mas sublima-a no processo do texto.

Como visão de pensamento global, a de Sebald é talvez desoladora. "Mas a verdade é que desconhecemos o que o arenque sente", Sebald escreve numa frase simples que ganha ainda mais força por estar rodeada de frases de fôlego e digressão (SEBALD, 1999, p.57). Conforme matamos, consumimos, torturamos e estudamos o arenque, falhamos em apreender sua absoluta alteridade, e em testemunhar a alteridade do mundo natural. No processo, esse mundo, o nosso mundo, desaparece de vista, como a captura de peixes no Mar do Norte (e agora, em todos os nossos mares) que ano a ano vem diminuindo. Contudo, o cosmopolitismo dessa visão, ainda que moderado, permanece poderoso e instigante. Como a modesta e reconhecidamente comprometida perspectiva ética de um único indivíduo que esmiúça a história da exploração humana do mundo natural, Sebald não chega a conclusões firmes, a nada além do ato de carregar testemunho. Se (ou como) é possível que esta ideia de carregar o testemunho da destruição de nosso meio ambiente se transforme em 
um programa político positivo para a mudança global, eis o que Sebald nos deixa, com nosso vocabulário poderosamente comprometido, a contemplar.

Traduzido por Omar Rodovalho

\section{REFERÊNCIAS BIBLIOGRÁFICAS}

ANDERSON, Amanda. Cosmopolitanism, Universalism, and the Divided Legacies of Modernity. In: CHEAH, Pheng e ROBBINS, Bruce (eds.). Cosmopolitics: Thinking and Feeling Beyond the Nation. Minneapolis: U Minnesota P, 1998.

ARCHIBUGI, Daniele e HELD, David. Cosmopolitan Democracy: An Agenda for a New World Order. Cambridge: Polity P, 1995.

BECK, Ulrich. The Cosmopolitan Manifesto. In: World Risk Society. Oxford: WileyBlackwell, 1999.

BENHABIB, Seyla. Another Cosmopolitanism. Oxford: Oxford UP, 2006.

BRENNAN, Timothy. At Home in the World: Cosmopolitanism Now. Cambridge: Harvard UP, 1997.

CLIFFORD, James. Traveling Cultures. In: GROSSBERG, Lawrence, NELSON, Cary, TRIECHLER, Paula A. (eds.) Cultural Studies. Nova Iorque: Routledge, 1992.

DeLILLO, Don. Cosmopolis. Nova Iorque: Scribner, 2003.

DERRIDA, Jacques. On Cosmopolitanism. In: On Cosmopolitanism and Forgiveness (trad. Mark Dooley e Michael Hughes). Londres: Routledge, 2007.

ESTEVE, Mary. Cosmopolis. In: STONELEY, Peter e WEINSTEIN, Cindy (eds.). A Concise Companion to American Fiction 1900-1950. Oxford: Wiley-Blackwell, 2008.

FINE, Robert e COHEN, Robin. Four Cosmopolitan Moments. In: VERTOVEC, Stephen e COHEN, Robin. Conceiving Cosmopolitanism: Theory, Context, and Practice. Oxford: Oxford UP, 2008.

KANT, Immanuel. Idea for a Universal History from a Cosmopolitan Perspective. In: Toward Perpetual Peace and Other Writings on Politics, Peace, and History (ed. Pauline Kleingeld). New Haven: Yale UP, 2006. . Toward Perpetual Peace. In: Toward Perpetual Peace and Other Writings on Politics, Peace, and History (ed. Pauline Kleingeld). New Haven: Yale UP, 2006. . Anthropology from a Pragmatic Point of View (trad. Robert Louden). Cambridge: Cambridge UP, 2006.

KRISTEVA, Julia. Crisis of the European Subject. Nova Iorque: Other P, 200. 
LOWE, Lisa. The Intimacies of Four Continents. In: STOLER, Ann Laura (ed.) Haunted by Empire. Durham: Duke UP, 2006.

MACGREGOR, Sherilyn. Reading the Earth Charter: cosmopolitan environmental citizenship or light green politics as usual?. Ethics, Place, and Environment 7: 1\&2 (March 2004).

MIGNOLO, Walter D. The Many Faces of Cosmo-polis: Border Thinking and Critical Cosmopolitanism. Public Culture (ed. Carol Breckenridge) 12: 3 (Fall, 2000).

POLLOCK, Sheldon I., BHABHA, Homi K., BRECKENRIDGE, Carol Appadurai. Cosmopolitanisms. Public Culture (ed. Carol Breckenridge) 12: 3 (Fall, 200o).

SANTNER, Eric. On Creaturely Life: Rilke, Benjamin, Sebald. Chicago e Londres: U of Chicago P, 2006.

SCHMITT, Carl. The Concept of the Political (trad. George Schwab). Chicago: U Chicago $\mathrm{P}, 2007$.

SEBALD, W. G. The Rings of Saturn (trad. Michael Hulse). Nova Iorque: New Directions, 1999.

SLAUGHTER, Joseph. Human Rights Inc.: The World Novel, Narrative Form, and International Law. Nova Iorque: Fordham UP, 2007.

SPIVAK, Gayatri C. Cultural Talks in the Hot Peace: Revisiting the Global Village. In: CHEAH, Pheng e ROBBINS, Bruce (eds.). Cosmopolitics: Thinking and Feeling Beyond the Nation. Minneapolis: U Minnesota P, 1998.

ZAMMITO, John. Kant, Herder, and the Birth of Anthropology. Chicago: U Chicago P, 2002. 

Resenha 
